\title{
Evolution of transversus abdominis plane infiltration techniques for postsurgical analgesia following abdominal surgeries
}

\author{
Jeffrey Gadsden' \\ Sabry Ayad ${ }^{2}$ \\ Jeffrey J Gonzales ${ }^{3}$ \\ Jaideep Mehta ${ }^{4}$ \\ Jan Boublik ${ }^{5}$ \\ Jacob Hutchins ${ }^{6,7}$ \\ 'Department of Anesthesiology, Duke \\ University Medical Center, Durham, \\ NC, ${ }^{2}$ Department of Anesthesiology \\ and Pain Management, Cleveland \\ Clinic, Cleveland, $\mathrm{OH},{ }^{3}$ Department \\ of Anesthesiology, University of \\ Colorado Hospital, Aurora, CO, \\ ${ }^{4}$ Department of Anesthesiology, UT \\ Health, The University of Texas Health \\ Science Center at Houston, Houston, \\ TX, ${ }^{5}$ Department of Anesthesiology, \\ NYU Langone Medical Center - \\ Hospital for Joint Diseases, New York, \\ NY, 'Department of Anesthesiology, \\ ${ }^{7}$ Department of Surgery, University of \\ Minnesota, Minneapolis, MN, USA
}

Correspondence: Jeffrey Gadsden Department of Anesthesiology, Duke University Medical Center, 230I Erwin Road, Durham, NC 27705-4699, USA

$\mathrm{Tel}+\mathrm{I} 91968 \mathrm{I} 6437$

Fax +I 9196848994

Email jeffgadsden@gmail.com
This article was published in the following Dove Press journal:

Local and Regional Anesthesia

10 December 2015

Number of times this article has been viewed

\begin{abstract}
Transversus abdominis plane (TAP) infiltration is a regional anesthesia technique that has been demonstrated to be effective for management of postsurgical pain after abdominal surgery. There are several different clinical variations in the approaches used for achieving analgesia via TAP infiltration, and methods for identification of the TAP have evolved considerably since the landmark-guided technique was first described in 2001. There are many factors that impact the analgesic outcomes following TAP infiltration, and the various nuances of this technique have led to debate regarding procedural classification of TAP infiltration. Based on our current understanding of fascial and neuronal anatomy of the anterior abdominal wall, as well as available evidence from studies assessing local anesthetic spread and cutaneous sensory block following TAP infiltration, it is clear that TAP infiltration techniques are appropriately classified as field blocks. While the objective of peripheral nerve block and TAP infiltration are similar in that both approaches block sensory response in order to achieve analgesia, the technical components of the two procedures are different. Unlike peripheral nerve block, which involves identification or stimulation of a specific nerve or nerve plexus, followed by administration of a local anesthetic in close proximity, TAP infiltration involves administration and spread of local anesthetic within an anatomical plane of the surgical site.
\end{abstract}

Keywords: pain, TAP, liposome bupivacaine

\section{Introduction}

In the age of health care reform, institutions are asking providers to continually improve the quality of care while reducing costs. Patient satisfaction with pain management is a critically important measure of quality health care. ${ }^{1}$ While opioids are effective analgesics, their use is frequently associated with adverse effects such as dizziness, nausea, sedation, constipation, and in some cases, respiratory depression. ${ }^{2}$ Guidelines suggest that opioid-sparing multimodal analgesia should be used whenever possible in order to optimize analgesic efficacy while minimizing the risk of opioid-related adverse events., ${ }^{2,3}$ Regional anesthesia techniques are an effective mode of analgesia, considered safe with a low risk for complications, and are a frequently utilized component in multimodal analgesic regimens. ${ }^{3-5}$ Transversus abdominis plane (TAP) infiltration is a regional anesthesia technique that provides analgesia to the anterior abdominal wall. Abdominal field blocks have been utilized for more than a century, but infiltration techniques used in TAP were developed and refined within the last 15 years. TAP infiltration has been demonstrated to be an effective regional anesthesia approach to controlling postsurgical pain, frequently allowing patients a faster recovery time after undergoing abdominal surgery. ${ }^{6-8}$ 


\section{Anatomy of the TAP}

The TAP is a potential anatomical space in the anterior wall that spans the entire abdomen between the internal oblique and transversus abdominis muscles (Figure 1). ${ }^{9}$ The anterior rami of the lower six thoracic nerves (T7-T12) and first lumbar nerve (L1) pass through the plane and provide somatic innervation to the anterior and lateral abdominal walls. ${ }^{6,10,11}$ The nerves are bound to the transversus abdominis muscle by a layer of fascia, suggesting that local anesthetics should be deposited underneath the fascial layer to ensure optimal analgesia. ${ }^{11}$ Detailed anatomic studies of the TAP have revealed individual variability in the extent of spinal nerve branching. In a cadaveric dissection study of innervation of the anterior abdominal wall ( $\mathrm{n}=20$ subjects) ${ }^{11}$ extensive branching was noted for T9-L1 starting at the anterior axillary line to the midline. In addition, a large, longitudinal plexus of communicating branches was observed within the TAP in the anterolateral abdominal wall lateral to the deep circumflex iliac artery. A second longitudinal plexus exists closer to the midline, running cephalocaudally with the inferior epigastric artery. ${ }^{11}$ Another cadaveric study noted individual variation in the dimensions of the lumbar triangle of Petit, usually situated just behind the highest point of the iliac crest (Figure 2), ${ }^{6,12,13}$ which serves as an anatomical landmark for TAP infiltration. The study also noted that the T9-L1 nerves held a relatively constant course in the TAP prior to the midaxillary line, but that branching after this point was commonly observed. ${ }^{9}$

\section{Evolution of TAP infiltration techniques}

TAP infiltration was originally characterized as a landmarkguided abdominal field block based on the lumbar triangle

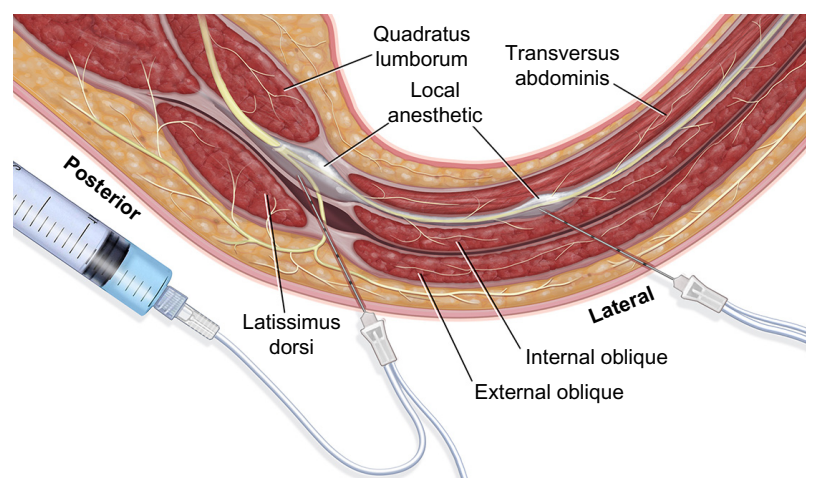

Figure I Muscular anatomy of the posterolateral abdominal wall.

Notes: The spinal nerves travel anteriorly between quadratus lumborum and latissimus dorsi before entering the plane between internal oblique and transversus abdominis muscles. Two possible infiltrative approaches are illustrated. Illustration courtesy of Pacira Pharmaceuticals, Inc.

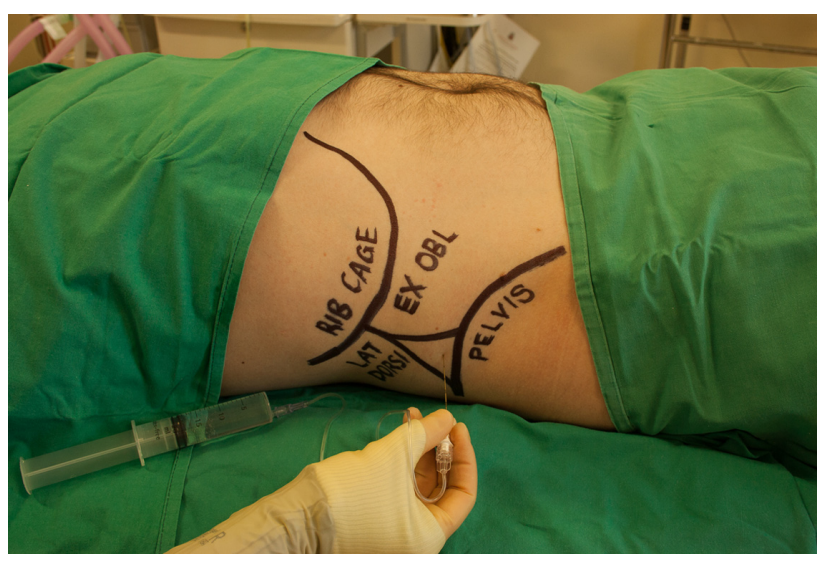

Figure 2 Surface anatomical landmarks used in transversus abdominis plane block. Note: Reproduced with permission from Webster $\mathrm{K}$. The transversus abdominis plane (TAP) block: abdominal plane regional anaesthesia. Update in Anaesthesia. 2008;24(I): 24-29.13 http://www.wfsahq.org/resources/update-in-anaesthesia. Abbreviations: EX OBL, external oblique; LAT DORSI, latissimus dorsi.

of Petit in $2001 .{ }^{12}$ Appropriate needle placement using the landmark technique resulted in a "pop" or "sensation of giving way", which indicated that the needle had reached the fascial plane between the internal oblique and transversus abdominis muscles. ${ }^{12}$ The technique, initially described as a field block or a regional abdominal field infiltration, was eventually referred to as a "TAP block" 7,14 This technique was evaluated and modified through a series of cadaveric and healthy volunteer studies. ${ }^{9,15-18}$ An alternative "double pop" method was described in which the needle is advanced perpendicularly until the first pop is felt in between the external and internal oblique muscles, and then advanced again until a second pop is felt, indicating entry into the transversus abdominis fascial plane. ${ }^{6,18}$

As spread of the local anesthetic is critical for analgesic efficacy, an ultrasound-guided (USG) technique was a logical progression for TAP infiltration. The initial USG approach involved transverse application of the ultrasound probe to the anterolateral abdominal wall where the three muscle layers are most distinct (Figure 3). ${ }^{19,20}$ The needle, as well as the hypoechoic layer of local anesthetic in the fascia, was visualized in the plane. ${ }^{20} \mathrm{~A}$ series of clinical studies evaluated the extent of analgesia in multiple surgical models, including prostatectomy, abdominal surgeries (bowel resections), appendectomy, cesarean section, and abdominal hysterectomy. Initial clinical results deviated from the landmark-based technique, as the spread of analgesia did not seem to be as extensive. ${ }^{21-25}$ Although the reason for this is not well understood, it has been suggested that the key objective in ultrasound is visualization of the spread of the injectate between the internal oblique and transversus 


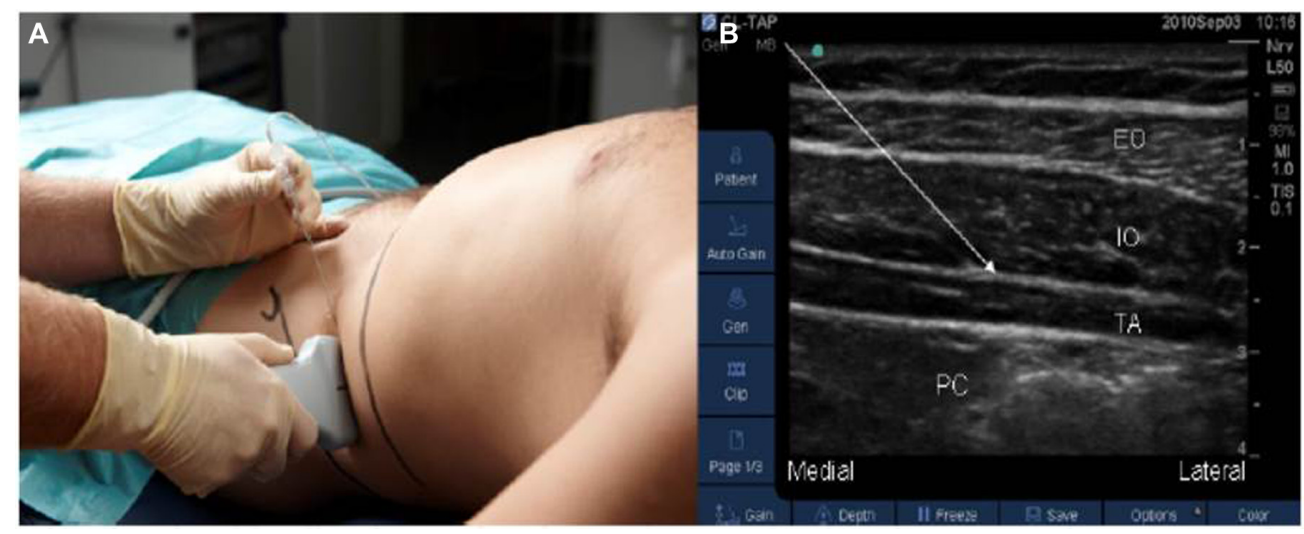

Figure 3 Ultrasound-guided lateral approach to transversus abdominis plane block.

Notes: $(\mathbf{A})$ is the external view and $(\mathbf{B})$ is the internal ultrasound image (the arrow shows the transversus abdominis plane). Reproduced from Børglum J, Jensen K. Abdominal surgery: advances in the use of ultrasound-guided truncal blocks for perioperative pain management. In: Derbel F, editor. Abdominal Surgery. Rijeka, Croatia: InTech; 2012:69-94 (https://creativecommons.org/licenses/by-nc/4.0/). ${ }^{19}$

Abbreviations: EO, external oblique; IO, internal oblique; TA, transversus abdominis; PC, peritoneal cavity.

muscles, possibly causing the operator to ignore the tactile pop that indicates optimal needle placement in the anatomical space underneath the fascial layer. ${ }^{8}$ In response to this clinical variation, the technique evolved further. Multiple and single injections as well as lateral, subcostal, and posterior approaches have all been described. ${ }^{17,19,24,26}$ A report describing four different approaches to TAP infiltration found that local anesthetic spread resulting from the posterior approach mirrored most closely the original landmark-guided triangle of Petit approach. ${ }^{17}$ Spread of local anesthetic was measured radiologically, and was found to cover T5-L1 levels using these techniques. ${ }^{17} \mathrm{~A}$ four-point single-shot technique that combines both the posterior and subcostal approaches has also been described and purportedly provides wider analgesic coverage. ${ }^{19}$ In sum, there are many factors that impact analgesic outcomes in TAP: in addition to method of nerve localization and needle placement, population type (pregnant vs nonpregnant, obese vs nonobese); surgical procedure; practitioner's level of skill; type, dose, and volume of local anesthetic used; timing of injection; and clinical assessments used all have an impacting role. ${ }^{8}$

\section{Key differences between TAP infiltration and peripheral nerve blocks}

A 2015 study $^{27}$ in 16 healthy volunteers evaluated cutaneous sensory block following TAP infiltration. It was determined that extent of spread was variable and nondermatomal, indicating that the specific nerves that are blocked as a result of a TAP infiltration likely vary from patient to patient based on their anatomy. ${ }^{27}$ The many nuances of the technique have led to a debate in the field: is there a need for standardization of techniques or technique nomenclature? The "TAP block family" and regional abdominal field infiltration have both been proposed to describe the group of techniques that have evolved from the initial triangle of Petit landmark technique. ${ }^{7,8}$ However, the fundamentals of the technique remain consistent across approaches: no specific nerve within the TAP is targeted; localization of the plane and the spread of local anesthetic within the plane are the key determinants of analgesia. ${ }^{19}$

Multiple surgeon-assisted approaches have been described, suggesting that techniques used to access the plane itself have also broadened. Intra-abdominal laparoscopic cameras operated by surgeons, rather than ultrasound, have been used to visualize the plane. For example, one report describes a technique developed to enable identification of a peritoneal bulge in the area of injection that confirms delivery of local anesthetic into the TAP. ${ }^{28}$ Other reports describe a surgeonassisted intraoperative transperitoneal approach in which the blunt-tipped block needle was advanced from inside the abdominal wall through the parietal peritoneum, into the transversus abdominis muscle, and then into the TAP. ${ }^{29,30}$ Direct visualization of local anesthetic spread in the TAP using blunt dissection of the oblique muscles has also been described. ${ }^{31}$ The goal of the surgeon-assisted approach is to conduct the same field block as traditional surgical infiltrative techniques where local anesthetic is deposited near the incision.

Whether local anesthetics are utilized for a peripheral nerve block or for infiltration, the objective is the same - to block the sensory response. However, key technical components diverge when comparing a peripheral nerve block to an infiltration technique. As described above, TAP infiltration comprises multiple approaches used to identify an anatomical 
plane, instead of a specific nerve or nerve plexus. This differs from peripheral nerve blocks as well as other field block approaches. For example, in a peripheral nerve block of the upper or lower extremity, USG and/or nerve stimulation are frequently used to identify the nerve that is to be blocked along with surrounding anatomy. ${ }^{19}$ The optimal needle position is near or toward that specific nerve, and spread of local anesthetic around the nerve is observed. ${ }^{32,33}$ Precision and ability to maintain appropriate needle placement are of the utmost importance in peripheral nerve blocks. ${ }^{19}$

\section{Conclusion}

While the objective of peripheral nerve block and TAP infiltration are similar in that both approaches block sensory response in order to achieve analgesia, the technical components of these two approaches are different. Unlike peripheral nerve block, which involves administration of a local anesthetic in close proximity to a specific nerve or nerve plexus, TAP infiltration is a field block technique in which a local anesthetic is administered into an anatomical plane.

\section{Acknowledgments}

Editorial assistance was provided by Peloton Advantage, LLC, supported by Pacira Pharmaceuticals, Inc. The authors were fully responsible for the content, editorial decisions, and opinions expressed in the current article. The authors did not receive an honorarium related to the development of this manuscript.

\section{Disclosure}

Dr Jeffrey Gadsden has received honoraria as a consultant for Pacira Pharmaceuticals, Inc. Dr Sabry Ayad is a speaker and consultant for Pacira Pharmaceuticals, Inc. Dr Jeffrey J Gonzales has received speaking fees from Pacira Pharmaceuticals, Inc. Dr Jaideep Mehta has received research support and speaking fees from Pacira Pharmaceuticals, Inc. Dr Jan Boublik is a consultant for Pacira Pharmaceuticals, Inc. Dr Jacob Hutchins has received research support as well as honoraria as a consultant and speaker's bureau member from Pacira Pharmaceuticals, Inc. He has also received honoraria from Halyard Health, Inc. as a speaker's bureau member. The authors report no other conflicts of interest in this work.

\section{References}

1. Berwick DM. Making good on ACOs' promise - the final rule for the Medicare shared savings program. N Engl J Med. 2011;365(19): 1753-1756.

2. Paice JA, Gordon DB, Contreras J, Jarzyna D. Safe use of opioids in hospitals. Sentinel Event Alert. 2012;49:1-5.
3. American Society of Anesthesiologists Task Force on Acute Pain Management. Practice guidelines for acute pain management in the perioperative setting: an updated report by the American Society of Anesthesiologists Task Force on Acute Pain Management. Anesthesiology. 2012;116(2):248-273.

4. Joshi GP, Beck DE, Emerson RH, et al. Defining new directions for more effective management of surgical pain in the United States: highlights of the inaugural Surgical Pain Congress ${ }^{\mathrm{TM}}$. Am Surg. 2014; 80(3):219-228

5. Petersen PL, Mathiesen O, Torup H, Dahl JB. The transversus abdominis plane block: a valuable option for postoperative analgesia? A topical review. Acta Anaesthesiol Scand. 2010;54(5):529-535.

6. Young MJ, Gorlin AW, Modest VE, Quraishi SA. Clinical implications of the transversus abdominis plane block in adults. Anesthesiol Res Pract. 2012;2012:731645.

7. Finnerty O, McDonnell JG. Transversus abdominis plane block. Curr Opin Anaesthesiol. 2012;25(5):610-614.

8. Lissauer J, Mancuso K, Merritt C, Prabhakar A, Kaye AD, Urman RD. Evolution of the transversus abdominis plane block and its role in postoperative analgesia. Best Pract Res Clin Anaesthesiol. 2014;28(2): $117-126$.

9. Jankovic ZB, du Feu FM, McConnell P. An anatomical study of the transversus abdominis plane block: location of the lumbar triangle of Petit and adjacent nerves. Anesth Analg. 2009;109(3):981-985.

10. Findlay JM, Ashraf SQ, Congahan P. Transversus abdominis plane (TAP) blocks-a review. Surgeon. 2012;10(6):361-367.

11. Rozen WM, Tran TM, Ashton MW, Barrington MJ, Ivanusic JJ, Taylor GI. Refining the course of the thoracolumbar nerves: a new understanding of the innervation of the anterior abdominal wall. Clin Anat. 2008;21(4):325-333.

12. Rafi AN. Abdominal field block: a new approach via the lumbar triangle. Anaesthesia. 2001;56(10):1024-1026.

13. Webster $\mathrm{K}$. The transversus abdominis plane (TAP) block: abdominal plane regional anaesthesia. Update in Anaesthesia. 2008;24(1):24-29. Available from: http://e-safe-anaesthesia.org/e_library/09/Transversus_ abdominis_plane_TAP_block_Update_2008.pdf. Accessed July 2, 2015 .

14. O'Donnell BD, McDonnell JG, McShane AJ. The transversus abdominis plane (TAP) block in open retropubic prostatectomy. Reg Anesth Pain Med. 2006;31(1):91.

15. Tran TM, Ivanusic JJ, Hebbard P, Barrington MJ. Determination of spread of injectate after ultrasound-guided transversus abdominis plane block: a cadaveric study. Br J Anaesth. 2009;102(1):123-127.

16. Barrington MJ, Ivanusic JJ, Rozen WM, Hebbard P. Spread of injectate after ultrasound-guided subcostal transversus abdominis plane block: a cadaveric study. Anaesthesia. 2009;64(7):745-750.

17. Carney J, Finnerty O, Rauf J, Bergin D, Laffey JG, Mc Donnell JG. Studies on the spread of local anaesthetic solution in transversus abdominis plane blocks. Anaesthesia. 2011;66(11):1023-1030.

18. McDonnell JG, O'Donnell BD, Farrell T, et al. Transversus abdominis plane block: a cadaveric and radiological evaluation. Reg Anesth Pain Med. 2007;32(5):399-404.

19. Børglum J, Jensen K. Abdominal surgery: advances in the use of ultrasound-guided truncal blocks for perioperative pain management. In: Derbel F, editor. Abdominal Surgery. Rijeka, Croatia: InTech; 2012:69-94.

20. Hebbard P, Fujiwara Y, Shibata Y, Royse C. Ultrasound-guided transversus abdominis plane (TAP) block. Anaesth Intensive Care. 2007;35(4):616-617.

21. McDonnell JG, O’Donnell B, Curley G, Heffernan A, Power C, Laffey JG. The analgesic efficacy of transversus abdominis plane block after abdominal surgery: a prospective randomized controlled trial. Anesth Analg. 2007;104(1):193-197.

22. Carney J, McDonnell JG, Ochana A, Bhinder R, Laffey JG. The transversus abdominis plane block provides effective postoperative analgesia in patients undergoing total abdominal hysterectomy. Anesth Analg. 2008;107(6):2056-2060 
23. McDonnell JG, Curley G, Carney J, et al. The analgesic efficacy of transversus abdominis plane block after cesarean delivery: a randomized controlled trial. Anesth Analg. 2008;106(1):186-191.

24. El-Dawlatly AA, Turkistani A, Kettner SC, et al. Ultrasound-guided transversus abdominis plane block: description of a new technique and comparison with conventional systemic analgesia during laparoscopic cholecystectomy. Br J Anaesth. 2009;102(6):763-767.

25. Niraj G, Searle A, Mathews M, et al. Analgesic efficacy of ultrasoundguided transversus abdominis plane block in patients undergoing open appendicectomy. Br J Anaesth. 2009;103(4):601-605.

26. Hebbard PD, Barrington MJ, Vasey C. Ultrasound-guided continuous oblique subcostal transversus abdominis plane blockade: description of anatomy and clinical technique. Reg Anesth Pain Med. 2010;35(5): 436-441.

27. Støving K, Rothe C, Rosenstock CV, Aasvang EK, Lundstrøm LH, Lange KH. Cutaneous sensory block area, muscle-relaxing effect, and block duration of the transversus abdominis plane block: a randomized, blinded, and placebo-controlled study in healthy volunteers. Reg Anesth Pain Med. 2015;40(4):355-362.

28. Chetwood A, Agrawal S, Hrouda D, Doyle P. Laparoscopic assisted transversus abdominis plane block: a novel insertion technique during laparoscopic nephrectomy. Anaesthesia. 2011;66(4):317-318.
29. Bharti N, Kumar P, Bala I, Gupta V. The efficacy of a novel approach to transversus abdominis plane block for postoperative analgesia after colorectal surgery. Anesth Analg. 2011;112(6):1504-1508.

30. Owen DJ, Harrod I, Ford J, Luckas M, Gudimetla V. The surgical transversus abdominis plane block - a novel approach for performing an established technique. BJOG. 2011;118(1):24-27.

31. Araco A, Pooney J, Araco F, Gravante G. Transversus abdominis plane block reduces the analgesic requirements after abdominoplasty with flank liposuction. Ann Plast Surg. 2010;65(4):385-388.

32. Keys to Success with Peripheral Nerve Blocks [webpage on the Internet] New York: NYSORA (The New York School of Regional Anesthesia); 2014. Available from: http://www.nysora.com/regional-anesthesia/4340keys-to-success-with-peripheral-nerve-blocks.html. Accessed June 30, 2015.

33. Upper Extremity Nerve Blocks: International Standardized Techniques [poster]. 2nd ed. New York: NYSORA (The New York School of Regional Anesthesia); 2015. Available from: http://www.nysora.com/educationaltools/3222-nysora-educational-posters.html. Accessed June 30, 2015.
Local and Regional Anesthesia

\section{Publish your work in this journal}

Local and Regional Anesthesia is an international, peer-reviewed, open access journal publishing on the development, pharmacology, delivery and targeting and clinical use of local and regional anesthetics and analgesics. The journal welcomes submitted papers covering original research, basic science, clinical studies, reviews \& evaluations,

\section{Dovepress}

guidelines, expert opinion and commentary, case reports and extended reports. The manuscript management system is completely online and includes a very quick and fair peer-review system, which is all easy to use. Visit http://www.dovepress.com/testimonials.php to read real quotes from published authors. 